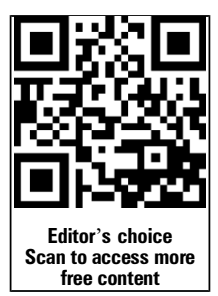

free content

\title{
Pleural mesothelioma and occupational and non-occupational asbestos exposure: a case-control study with quantitative risk assessment
}

\author{
Daniela Ferrante, ${ }^{1}$ Dario Mirabelli, ${ }^{2,3}$ Sara Tunesi, ${ }^{1}$ Benedetto Terracini, ${ }^{2,3}$ \\ Corrado Magnani ${ }^{1,3}$
}

- Additional material is published online only. To view please visit the journal online (http://dx.doi.org/10.1136/ oemed-2015-102803).

${ }^{1}$ Department of Translational Medicine, Unit of Medical Statistics and Cancer Epidemiology, CPO Piemonte and University of Piemonte Orientale, Novara, Italy ${ }^{2}$ Unit of Cancer Epidemiology, CPO Piemonte and University of Turin, Turin, Italy

${ }^{3}$ Interdepartmental Centre G. Scansetti for Studies on Asbestos and other Toxic Particulates, University of Turin, Turin, Italy

\section{Correspondence to} Daniela Ferrante, Department of Translational Medicine, Unit of Medical Statistics and Cancer Epidemiology, CPO Piemonte and University "Amedeo Avogadro" of Piemonte Orientale, V. Solaroli 17, 28100 Novara, Italy: daniela.ferrante@med.uniupo.it

Received 2 January 2015 Revised 22 June 2015 Accepted 14 July 2015 Published Online First 11 August 2015

\section{SLinked}

- http://dx.doi.org/10.1136/ oemed-2015-103233

\section{CrossMark}

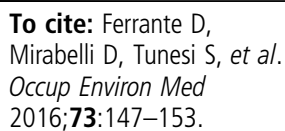

\section{ABSTRACT}

Objectives Casale Monferrato (north west Italy) is an area with an exceptionally high incidence of mesothelioma caused by asbestos contamination at work and in the general environment from the asbestoscement Eternit plant that was operational until 1986 The purpose of this study was to quantify the association between pleural malignant mesothelioma (PMM) and asbestos cumulative exposure using individual assessment of environmental and domestic exposure, as well as of occupational exposure. Methods This population-based case-control study included cases of PMM diagnosed between January 2001 and June 2006 among residents in the Casale Monferrato Local Health Authority. Population controls were randomly sampled, matched by age and sex to cases. Cumulative exposure was estimated to account for the lifelong exposure history. Analyses were conducted using unconditional logistic regression models adjusting for gender, age at diagnosis and type of interview (direct or proxy respondents).

Results 200 PMM cases of 223 eligible cases (89.7\%) and $348(63 \%)$ of 552 eligible controls accepted to be interviewed. ORs increased with cumulative exposure index $(p<0.0001)$ from 4.4 (Cl 95\% 1.7 to 11.3$)(<1 \mathrm{f} /$ $\mathrm{mL}$-years) to 62.1 (Cl $95 \% 22.2$ to 173.2$)(\geq 10 \mathrm{f} / \mathrm{mL}$ years). Among subjects never occupationally exposed, corresponding ORs were 3.8 (Cl 95\% 1.3 to 11.1) and 23.3 (Cl 95\% 2.9 to 186.9) (reference: background level of asbestos exposure). ORs of about 2, statistically significant, were observed for domestic exposure and for living in houses near buildings with large asbestos cement parts.

Conclusions Risk of PMM increased with cumulative asbestos exposure and also in analyses limited to subjects non-occupationally exposed. Our results also provide indication of risk associated with common sources of environmental exposure and are highly relevant for the evaluation of residual risk after the cessation of asbestos industrial use.

\section{INTRODUCTION}

A large number of developed, industrialised countries have banned or restricted asbestos use in the past 30 years. Nevertheless, asbestos exposure is still widespread in the world: besides active occupational exposure that is estimated to affect about 125 million men and women, ${ }^{1}$ a large number of people are exposed to asbestos in areas that may

\section{What this paper adds}

- Previous studies by us investigated the effects of different exposure routes (occupational, environmental, domestic) separately and on a qualitative basis. Here we focus on the separate contribution of non-occupational (environmental and domestic) exposure to pleural malignant mesothelioma risk using estimated quantitative exposure.

- A cumulative exposure trend in the risk of pleural malignant mesothelioma was observed with increasing non-occupational exposure, as well as with occupational exposure.

- An increased risk of pleural malignant mesothelioma was observed for domestic exposure from asbestos exposed family members.

- An increased risk was observed from self-reported exposure to asbestos in place.

remain in place for decades after the enforcement of asbestos bans. To the best of our knowledge, no reliable global estimate exists of the number of people affected by environmental or domestic exposure linked to asbestos mining or industrial processing or other asbestos use. Each year about 89000 people die from asbestos-related diseases such as lung cancer, mesothelioma and asbestosis. ${ }^{2}$

The association between environmental exposure to asbestos and pleural malignant mesothelioma (PMM) has been investigated in a few studies conducted in areas with significant asbestos mining or processing activities. These reflected the levels of exposure in the general environment when mines and industries were active. ${ }^{3-8}$ Other case-control studies investigated the risk factors for PMM in populations living in areas not affected by specific environmental sources of asbestos exposure. ${ }^{9-13}$ No formal studies, as to our knowledge, explored the relationship between cumulative exposure and PMM after non-occupational exposures or investigated the risk associated with asbestos materials in place in living areas.

The area of Casale Monferrato in Italy showed an extremely high incidence of PMM. The average annual incidence (definite diagnosis) in the period 
1990-2010 was 27.3 (per 100 000) among men and 15 (per $100000)$ among women, about 10 times higher than the corresponding Italian incidence rates. ${ }^{14}{ }^{15}$ An asbestos-cement (AC) factory (Eternit) was active in the town of Casale Monferrato for 80 years, until $1986,{ }^{16}$ and was the major source of asbestos pollution. $^{8}{ }^{17}$ Our research group conducted several studies on the effects of asbestos exposure in the area. However, our previous reports considered the association of PMM with asbestos exposure separately for occupational, environmental and famil$\mathrm{ial} /$ domestic routes of exposures and used qualitative exposure assessment. ${ }^{7} 81617$ That is unsatisfactory as individuals experience multiple circumstances and routes of exposure whose effect on PMM risk could not be separately assessed; thus, the exposure-response relation could not be estimated separately for occupational and environmental exposure. The present study was carried out to overcome these limitations and moreover, to update risk evaluation after 20 years from the cessation of industrial activity. A more refined assessment of asbestos exposures was performed: frequency, duration and intensity of exposure were estimated and a cumulative exposure index was computed. We present estimates of PMM risk by this cumulative exposure index with consideration of all sources of exposure.

\section{METHODS}

The population-based case-control study included the incident cases of PMM diagnosed between 1 January 2001 and 30 June 2006 among residents of the Casale Monferrato Local Health Authority (LHA), and a random sample of the corresponding general population. The LHA included the town of Casale Monferrato and the surrounding area, comprising roughly 60 towns and villages of different sizes. The total population on December 312001 was 117680 (of whom 35238 lived in Casale Monferrato).

Cases were actively searched in the units of pathology, pneumology, oncology, internal medicine, thoracic surgery and radiotherapy of the hospitals serving the study area. Only cases with morphological (histological and/or cytological) confirmation of diagnosis were included. Controls were randomly selected from the population rosters of the LHA of Casale Monferrato. Cases and controls were matched by date of birth ( \pm 18 months) and gender. To increase power in the younger age classes, the casecontrol ratio was 1:2 for cases 60 years and older, and 1:4 for younger cases.

Cases were invited to the study by their attending clinician, while controls were invited by letter after their respective general practitioners (GPs) were duly informed. All participating subjects received written detailed information on the study, and signed consent forms for the interview and the processing of sensitive personal data.

When the invited subjects died or were physically unfit, proxy interviews were accepted, usually with the spouse or a son or daughter (table 1). Cases and controls (or their respondents) were interviewed using a standardised questionnaire, administered by trained interviewers (further details provided in the online supplementary methods).

\section{Coding of occupational histories}

Job titles were coded according to the International Standard Classification of Occupations, ${ }^{18}$ and trades according to the Statistical classification of economic activities in the European Community. ${ }^{19}$
Table 1 Case-control study on pleural mesothelioma in the Casale Monferrato area

\begin{tabular}{|c|c|c|}
\hline & $\begin{array}{l}\text { Cases } \\
\mathrm{N}(\%)\end{array}$ & $\begin{array}{l}\text { Controls } \\
\mathrm{N}(\%)\end{array}$ \\
\hline \multicolumn{3}{|l|}{ Sex } \\
\hline Male & $127(63.5)$ & $220(63.2)$ \\
\hline Female & $73(36.5)$ & $128(36.8)$ \\
\hline \multicolumn{3}{|l|}{ Type of interview } \\
\hline To subject & $108(54.0)$ & $323(92.8)$ \\
\hline To relatives & $92(46.0)$ & $25(7.2)$ \\
\hline \multicolumn{3}{|l|}{ Vital status } \\
\hline Deceased & $48(24.0)$ & $1(0.3)$ \\
\hline Alive & $152(76.0)$ & 347 (99.7) \\
\hline \multicolumn{3}{|l|}{ Residence at the interview } \\
\hline Casale Monferrato (town) & $134(67.0)$ & $105(30.2)$ \\
\hline Other towns of the LHA & $66(33.0)$ & $243(69.8)$ \\
\hline Age (years; mean $\pm S D$ ) & $68.3(11.4)$ & $63.3(11.6)$ \\
\hline \multicolumn{3}{|l|}{ Duration of interview } \\
\hline (minutes; mean \pm SD) & $74.2(18.3)$ & $70.7(17.1)$ \\
\hline
\end{tabular}

\section{Exposure assessment}

The evaluation of asbestos exposure (occupational, environmental, domestic) was conducted blindly to the case/control status by an experienced rater (DM).

As individuals often had multiple exposure circumstances (work and not work-related), the exposure assessment took into account their whole exposure history and computed a single exposure index, reflecting the contribution of all sources. Exposures unrelated with work included living in proximity to industrial or natural sources of airborne asbestos (environmental exposures), sharing home with individuals occupationally exposed to asbestos (familial exposure), having asbestoscontaining materials installed at home or handling such materials during home repairs or leisure-time activities (domestic exposures).

Any particular exposure circumstance may entail multiple exposure patterns, which have been separately assessed.

As regards occupational exposure, at least one and potentially many exposure patterns were assigned to every job held by a study subject. For instance, if a job entailed regular working shifts in a brake-lining production department, followed by daily short duty periods spent cleaning the plant exhaust system, two different exposure patterns were assigned.

The most appropriate reference value for fibre concentration in each exposure pattern was chosen from collections of fibre measurements organised by job, industry and calendar period available from the literature and the web. ${ }^{20} 21$ Fibre measurements, furthermore, were available for asbestos industries active over the past four decades in Piedmont, including the Balangero asbestos mine, AC production, asbestos-textile works, and production of brake and clutch linings. Such measurements were carried out partly by public laboratories under the request of health and safety inspectors, and partly by company laboratories which were later registered by health and safety inspectors. These were retrieved and then entered into a computerised database, which contributed to the EXPOSYN database. ${ }^{22}$

To guide and document the exposure assessment process, the rater first completed a preliminary step. Based on the job description provided at the interview, a score was assigned to 
the exposure determinants included in a fixed list, including active and passive exposures. Scores were not intended to directly drive exposure assessment, but their pattern drew exposure scenarios, documenting how the rater reconstructed each exposure circumstance. This step accomplished, exposure was assessed along the four axes of probability, frequency, intensity and duration.

Probability of occupational exposure was classified as definite, probable, possible and unlikely. Exposure was considered definite when reported at interview or known to the rater. It was classified as unlikely when it had not been reported at interview and the rater had no knowledge of its occurrence under the specific circumstance being evaluated or other plausibly similar circumstances. Intermediate conditions, that is, exposure neither reported nor denied at interview but known to the rater to have occurred under the same or similar circumstances, could be classified as probable (if prevalence of exposure in the specific job, industry and period was estimated to be high) or possible (if prevalence was estimated to be low). Self-report of exposure was decisive for the assessment of exposures due to presence or use of asbestos-containing materials at home.

Frequency was assessed as the time spent under the exposure pattern under evaluation, relative to the duration of a standard $8 \mathrm{~h}$ work-shift. It was assigned according to the job description provided at interview, which included a question on the amount of time spent carrying out the different tasks entailed by each job. If no direct estimate could be obtained at interview, information provided by other interviewees engaged in similar work activities and the personal experience of the rater were taken into account.

Intensity was rated according to an ordinal scale, arranged in eight increasing steps, one order of magnitude apart. The lowest level corresponds to fibre concentrations in areas without man-made or natural sources $(<0.3$ fibres $/ \mathrm{L}(\mathrm{f} / \mathrm{L}))$ and the highest ones to those typical of unprotected tasks, in presence of very powerful sources of airborne fibres (30-300 fibres $/ \mathrm{mL}$ $(\mathrm{f} / \mathrm{mL}))$ and eventually, under the influence of other critical factors such as tight and unventilated spaces $(\geq 300 \mathrm{f} / \mathrm{mL})$. Each exposure pattern was assigned one of such levels and was, thus, attributed the corresponding fibre concentration interval.

Duration of exposure for a given period was computed as the difference between the year of start and year of end, or 6 months if both occurred in the same year.

For every occupational exposure pattern, the exposure index was computed by multiplying frequency, intensity and duration. Frequency and duration were treated as continuous variables. As intensity had been assessed as a fibre concentration interval spanning one order of magnitude, it was first converted to a point estimate: the interval midpoint on a log scale. The midpoint for background intensity was set to $0.1 \mathrm{f} / \mathrm{L}$. The resulting exposure index had the dimension of fibre per millilitre years (f/mL-years) and background intensity exposures correspond to a lifetime cumulative exposure of $0.03 \mathrm{f} / \mathrm{mL}$-years. Probability of exposure was used to selectively include in analyses only exposure patterns fulfilling predefined criteria: only definite, definite and probable, or all exposures (definite, probable and possible).

A similar procedure was applied to non-occupational exposure circumstances.

Assessment of environmental exposures was based on the residential distance from identified neighbouring source(s) and from the source characteristics that may determine its emissions. For non-industrial sources, such as spaces paved with finely broken AC tailings, assessment was based only on the distance from home and this surface. For industrial sources, we also took into account the type-whether involving direct use of asbestos or of asbestos-containing materials-and level of production, asbestos consumption and calendar period of exposure to account for changes in production volume and in use of asbestos. These factors contributed to allocate a near field $(30-300 \mathrm{f} / \mathrm{L})$ or a far field $(3-30 \mathrm{f} / \mathrm{L})$ exposure level, relative to a specific source, or a level corresponding to the diffuse presence of individually unidentifiable sources $(0.3-3 \mathrm{f} / \mathrm{L})$, as in major urban areas or lastly, background exposure. When only information on residential distance and type of production were available to the rater, the criteria developed in one of our previous studies were used (see online supplementary appendix 1 ).

In case of familial/domestic exposures, intensity was assessed according to: characteristics of the asbestos-containing material reported at interview to be present at home (asbestos type and content, friability, surface damage, enclosure), type of contact (active, passive) and potential for mechanical damage associated with interventions on that material, as described at interview. Such circumstances, and in particular some leisure-time or home-repair activities involving the use of asbestos-containing materials, have the same determinants of exposure intensity as occupation and may entail exposure levels comparable to those experienced at work. The same criteria were, therefore, used along with additional references. ${ }^{23}$ Consideration was given to the fact that non-occupational exposures may last longer than a standard work shift, by allowing for frequency indices larger than 100\%: environmental and domestic exposures were typically assigned a standard $300 \%$ frequency index. ${ }^{24}$

Study subjects for whom no occupational and nonoccupational circumstances exceeded the background exposure level on the intensity scale were considered as a reference group. For all other study subjects, the cumulative exposure index was computed as the sum of all of their exposure indices. All exposures (definite, probable and possible) were included in the calculation for the main analysis. Analyses restricted to definite only and to definite plus probable exposures were also carried out, along with analyses limited to the exposures contributed by specific routes (occupational, environmental, famil$\mathrm{ial} /$ domestic) and analyses stratified by type of interview (direct or proxy).

\section{Data management and analysis}

Data were recorded in a standard data base (Microsoft Access) and were analysed using SAS V8, Stata V.11 and R. The main data analyses were based on unconditional logistic regression, adjusting all models for gender, age at diagnosis and type of interview (with subject vs with proxy). Statistical significance was set at 0.05 .

\section{RESULTS}

The study base included 223 eligible cases (mean age: 68.4; SD 11.3; males: 62\%) and 552 controls (mean age: 65.4; SD: 12.1; males: $61 \%)$. Two hundred cases $(89.7 \%)$ and $348(63 \%)$ controls accepted the invitation and were interviewed (table 1). The ascertained cases represented $96 \%$ of all incident cases of PMM registered by the regional mesothelioma registry in the corresponding area during the study period (DM personal communication). Distribution by sex of participating cases and controls was similar. Cases were older than controls because of the oversampling of controls matched to cases under 60 and the different age distribution of non-participating controls. Interviews took slightly longer among cases than among controls. Interviews were face to face in $54 \%$ of the cases (due to death or poor health condition, $46 \%$ of interviews were with a close 
relative) and for nearly all controls. Such differences were statistically significant and these variables were adjusted for in the analyses.

Table 2 presents results on PMM risk by classes of the cumulative exposure index. Classes were defined according to the logarithmic nature of the cumulative exposure index scale. Analyses show a constant trend of increasing OR with increasing exposure. A similar trend was observed when the analyses were restricted to subjects with non-occupational exposure. The OR was already significantly increased in the lowest category of exposure, corresponding to 'up to $1 \mathrm{f} / \mathrm{mL}$-years' class.

The 'upper exposure' categories are not corresponding for occupational and non-occupational exposures because this is an open category, including a different range of values for the two routes of exposure. Mean and range of fibre/mL-years are reported in table 2 . The mean duration of exposure ranges from 28 years (SD 17) for the subjects included in $<1 \mathrm{f} / \mathrm{mL}$-years category to 53 years (SD 17) for the subjects included in $\geq 10 \mathrm{f} / \mathrm{mL}$ years category.

Only 20 cases and 9 controls (out of respectively 200 and 348 , of which 116 and 147 were assessed as occupationally exposed) had been employed in the AC industry, a proportion that is not surprising given that the Casale Monferrato plant had closed operations in 1986 and two-thirds of the cohort members have died.

Analysis restricted to 'definite' only or to 'definite and probable' exposures are shown in online supplementary table S1. The results of analyses restricted to occupational, environmental and familial/domestic exposure circumstances are reported in online supplementary table S2. In online supplementary table S3 we show the ORs by cumulative exposure, stratified according to interview type, direct or proxy. Higher ORs were observed when considering subjects interviewed face to face versus subjects with a proxy interview.

Table 3 shows the risk of PMM in relation to occupational asbestos exposure of family members. Each category of membership was included as a dummy variable. A significantly increased OR was observed when father or mother or spouse were occupationally exposed to asbestos. An increase, close to statistical significance, was also present for other family members

Table 2 Case-control study on pleural mesothelioma in the Casale Monferrato area

\begin{tabular}{|c|c|c|c|}
\hline Fibre/mL-years & $\begin{array}{l}\text { Cases } \\
\text { N (\%) }\end{array}$ & $\begin{array}{l}\text { Controls } \\
\mathrm{N}(\%)\end{array}$ & OR $(95 \% \mathrm{CI})$ \\
\hline \multicolumn{4}{|l|}{ All subjects } \\
\hline background level $(<0.1)$ & $8(4.0)$ & $106(30.5)$ & 1 (ref) \\
\hline$\geq 0.1-<1$ & $26(13.0)$ & $108(31.0)$ & 4.4 (1.7 to 11.3$)$ \\
\hline$\geq 1-<10$ & $113(56.5)$ & $115(33.0)$ & 17.5 (7.3 to 41.8$)$ \\
\hline $\begin{array}{l}\geq 10 \text { (mean of fibres in this } \\
\text { class: } 201 \text {; range of fibres in } \\
\text { this class: } 10-4128 \text { ) }\end{array}$ & $53(26.5)$ & $19(5.5)$ & $62.1(22.2$ to 173.2$)$ \\
\hline Total & $200(100.0)$ & $348(100.0)$ & \\
\hline \multicolumn{4}{|c|}{ Non-occupationally exposed only } \\
\hline Background level $(<0.1)$ & $7(8.3)$ & $85(42.3)$ & 1 (ref) \\
\hline$\geq 0.1-<1$ & $15(17.9)$ & $58(28.9)$ & $3.8(1.3$ to 11.1$)$ \\
\hline$\geq 1-<10$ & $57(67.9)$ & $56(27.9)$ & 14.8 (5.7 to 38.6$)$ \\
\hline $\begin{array}{l}\geq 10 \text { (mean of fibres in this } \\
\text { class: } 16 ; \text { range of fibres in } \\
\text { this class: } 10-24.2 \text { ) }\end{array}$ & $5(6.0)$ & $2(1.0)$ & 23.3 (2.9 to 186.9 ) \\
\hline Total & $84(100.0)$ & $201(100.0)$ & \\
\hline
\end{tabular}

(table 3). Having a family member (any category) occupationally exposed to asbestos doubles the risk of PMM. Family members of 33 cases $(16 \%)$ and 26 controls $(7 \%)$ were reported to have brought work clothes home for cleaning. The OR only changed negligibly when using different procedures in controlling for direct occupational exposure, that is, adjustment or stratification. The results by exposure membership categories could not be mutually adjusted because of collinearity that precluded model fit.

Table 4 shows the results on risk associated with domestic exposure due to the use of asbestos-containing tools or the presence of AC materials at home or around it. Each exposure is included as a dummy variable. The OR for having paved the garden or courtyard with AC tailings (a relatively common practice and a source of exposure in the Casale Monferrato area) was 3.4 (95\% CI 1.4 to 8.4; adjusted for occupational exposure in $\mathrm{AC}$ industry). The increased ORs linked to having an $\mathrm{AC}$ roof $(\mathrm{OR}=2.4 ; 95 \% \mathrm{CI} 1.4$ to 4.2$)$ or $\mathrm{AC}$ buildings close to the house $(\mathrm{OR}=1.9 ; 95 \%$ CI 1.2 to 3.2$)$ were also statistically significant. These analyses were conducted using either adjustment or stratification by occupational exposure, with very similar results.

\section{DISCUSSION}

This population-based case-control study was conducted to improve knowledge on the relationship between PMM and quantitative exposure to asbestos, with special consideration of non-occupational and the general low-level of exposures, based on the evidence arising from the area of Casale Monferrato (Italy). We developed an interest for the area some 30 years ago because it was the location of the largest and oldest AC factory in Italy. We studied both the workers ${ }^{16}$ their families, ${ }^{25}$ and the risk factors for PMM in the local population. ${ }^{8}{ }^{17}$ The extremely high incidence of PMM in the area made it possible to conduct large studies as the present one, even if PMM is a rare disease. Aim of this study was to fully account for the joint contribution of occupational and non-occupational exposures to PMM risk and central to this effort was exposure assessment. Moreover, we aimed at updating previous results after the cessation of asbestos cement production in the area.

Information on exposure was based on data collected at interview and on the expert assessment of asbestos exposure. Expert-based exposure assessment has been criticised because of its lack of reproducibility and transparency. ${ }^{26}$ Despite such limitations, it is still considered to be state-of-the-art: alternative and more formal strategies for exposure assessment are only just being developed. ${ }^{27}{ }^{28}$ In our study, in order to enhance internal consistency and avoid differential exposure assessment and to document the rater's assumptions, exposure determinants were scored before quantitatively assessing the exposure circumstances. Non-differential error in exposure assessment, however, may have occurred. It has been shown that random error in exposure measurement, or a combination of random errors with systematic (but non-differential) underestimation or overestimation, leads to an attenuation of the exposure-response relationship when data are analysed by categorising a continuous exposure variable at predefined cut-points. ${ }^{29}$

A large number of different occupational and nonoccupational exposure circumstances were described by the study subjects and the most common were those associated with industrial activities and sources in Casale Monferrato. Fibre concentration measurements were available for only a minority and in recent periods. We took advantage of available data, with gaps completed on the basis of assessor's expertise. The 
Table 3 Case-control study on pleural mesothelioma in the Casale Monferrato area

\begin{tabular}{|c|c|c|c|c|c|c|}
\hline \multirow[t]{2}{*}{ Exposed family members } & \multirow{2}{*}{$\begin{array}{l}\text { Cases } \\
\mathrm{N}(\%)\end{array}$} & \multicolumn{2}{|l|}{ Controls } & \multirow{2}{*}{$\begin{array}{l}\text { Cases } \\
\text { N (\%) }\end{array}$} & \multicolumn{2}{|l|}{ Controls } \\
\hline & & $\mathrm{N}(\%)$ & $\mathrm{OR}^{\mathrm{adj}}(95 \% \mathrm{Cl})$ & & $\mathrm{N}(\%)$ & $\mathrm{OR}^{\mathrm{C}}(95 \% \mathrm{Cl})$ \\
\hline Father and/or mother & $19(9.5)$ & $21(6.0)$ & 2.6 (1.3 to 5.5$)$ & $17(9.4)$ & $19(5.6)$ & $3.1(1.4$ to 6.5$)$ \\
\hline Spouse & $14(7.0)$ & $8(2.3)$ & $2.6(0.9$ to 7.5$)$ & $12(6.7)$ & $8(2.4)$ & $2.2(0.7$ to 6.8$)$ \\
\hline Other & $9(4.5)$ & $7(2.0)$ & $2.2(0.7$ to 7.1$)$ & $7(3.9)$ & $6(1.8)$ & $2.5(0.7$ to 8.8$)$ \\
\hline Any family members & $38(19.0)$ & $35(10.1)$ & $2.2(1.2$ to 4.0$)$ & $33(18.3)$ & $32(9.4)$ & $2.4(1.3$ to 4.4$)$ \\
\hline No family members/cohabitants occupationally exposed to asbestos & $162(81.0)$ & $313(90.0)$ & 1 (ref) & $147(81.7)$ & $307(90.6)$ & 1 (ref) \\
\hline
\end{tabular}

Risk of mesothelioma in relation to occupational asbestos exposure of family members (having vs not having an exposed family member)

The models are adjusted for age, sex, type of interview. The reference category corresponds to subjects with no family members occupationally exposed to asbestos.

$O R^{c}: O R$ in the stratum of subjects with no occupation in the $A C$ industry.

$O R^{\text {adj: }}$ OR adjusted by occupational exposure to asbestos in the AC industry.

information on airborne asbestos fibre concentration in Casale Monferrato were presented by Maule et $a l^{17}$ and are only summarised here. Fibre concentration was about $10 \mathrm{f} / \mathrm{L}$ close to the factory and about $1 \mathrm{f} / \mathrm{L}$ elsewhere in the town in 1985; 10 years later it decreased to $1 \mathrm{f} / \mathrm{L}$ and less than $1 \mathrm{f} / \mathrm{L}$, respectively. Although the concentration of airborne asbestos fibres did not appear very high, all reports underlined the high proportion of long amphibole fibres. Further, even the oldest measurements were taken when the factory had already downscaled its activity, 1 year before its shut down. Two reports on lung asbestos fibre burden from the area of Casale Monferrato ${ }^{30} 31$ confirmed the high exposure of the resident population and clearly underlined the exposure to long amphibole fibres. In the study by Barbieri et $a l,{ }^{30}$ the amphibole fibres were regularly found among the eight mesothelioma patients considered (three patients with residency periods in Casale Monferrato), whereas chrysotile was present in only two cases and even then it was not the predominant type of fibre. Chrysotile is less persistent and the predominance presence of amphiboles could be a marker of environmental contamination from the 'Eternit' plant in Casale Monferrato. Hodgson and Darnton ${ }^{32}$ stated that per unit fibre exposure mesothelioma risk from amphiboles exposure is far more greater than that from chrysotile exposure.

The assessment of non-occupational exposures associated with the presence or use of asbestos-containing materials at home depended on the self-reporting of exposure and may have been affected by recall bias.

The study only included cases of PMM with diagnosis confirmed after microscopic examination of histological and/or cytological samples, identified through active search in the area referral hospitals. Identification was complete, as the cases accounted for over $95 \%$ of all incident cases arising in this population during the study period, according to the regional mesothelioma registry (DM, personal communication).
The study was restricted to PMM to reduce heterogeneity in the group of cases: since pleural and peritoneal MM show different incidence patterns by latency and exposure level, we deemed it inappropriate to pool them together. ${ }^{33}$ Controls were randomly sampled from the residents of the area: individual matching by age and gender was used to keep the two series comparable. Participation was almost 90\% for cases and 63\% for controls: corresponding figures in our previous case-control study were $89 \%$ and $83 \%$, respectively, but the proportion of living subjects was much higher in the present data.

A systematic review on the quantitative relationship between PMM and asbestos exposure was carried out for the Second Italian Consensus Conference on Malignant Mesothelioma of the Pleura. ${ }^{34}$ It documented that MM occurrence increased with cumulative exposure to asbestos. Our results confirm that conclusion, observing a sharp increase in PMM risk with cumulative exposure even at low and very low-levels. The exposureresponse relationship appeared sharper when the analyses were limited to directly interviewed subjects. It seemed steeper when not only definite, but also probable and possible exposures were taken into account; however, the ORs in the corresponding exposure categories had wide and overlapping CIs. When the cumulative exposure index was calculated by route of exposure (occupational, environmental, familial/domestic), the ORs by exposure category did not change significantly across the three different routes, but were systematically lower than in the main analysis, as shown in table 2 . This attenuation is due to the fact that the reference exposure category included individuals who were exposed by the other routes of exposure.

Only a limited number of studies on MM had previously been carried out in general populations and comparison of results was made difficult by differences in the diseases included (all MM or PMM), in assessment of exposure and in criteria of analysis.

Table 4 Case-control study on pleural mesothelioma in the Casale Monferrato area

\begin{tabular}{lcccccc}
\hline Type of exposure & Cases & Controls & OR $^{\text {adj }}$ (95\% Cl) & Cases & Controls & OR $^{\mathrm{C}}(\mathbf{9 5 \%}$ Cl) \\
\hline Asbestos-cement (AC) roof & $60(30)$ & $75(21.6)$ & $2.4(1.4$ to 4.2$)$ & $55(30.5)$ & $72(21.2)$ & $2.5(1.4$ to 4.5$)$ \\
Use of utensils of asbestos material & $41(20.5)$ & $86(24.7)$ & $1.3(0.7$ to 2.3$)$ & $39(21.7)$ & $86(25.4)$ & $1.2(0.7$ to 2.2$)$ \\
Garden or courtyard pavement with AC tailings & $18(9)$ & $13(3.7)$ & $3.4(1.4$ to 8.4$)$ & $16(8.9)$ & $12(3.5)$ & $3.6(1.4$ to 9.2$)$ \\
AC buildings in the garden or courtyard & $102(51)$ & $147(42.2)$ & $1.9(1.2$ to 3.2$)$ & $91(50.5)$ & $142(41.9)$ & $2.1(1.2$ to 3.4$)$ \\
Any of the above categories & $152(76)$ & $221(63.5)$ & $1.9(1.2$ to 3.0$)$ & $137(76.1)$ & $214(63.1)$ & $2.0(1.2$ to 3.2$)$ \\
None of the above categories & $48(24)$ & $127(36.5)$ & 1 (ref) & $43(23.9)$ & $125(36.9)$ & 1 (ref) \\
\hline
\end{tabular}

Risk of mesothelioma in relation to environmental and domestic exposure to asbestos with reference to the entire life history (exposed vs not exposed).

The models are adjusted for age, sex, type of interview. The reference category corresponds to subjects not being exposed to any of the categories.

$\mathrm{OR}^{\mathrm{C}}$ : OR in the stratum of subjects with no occupation in the $A C$ industry

$O R^{\text {adj. }}$ OR adjusted by occupational exposure to asbestos in the $A C$ industry 
Iwatsubo et $a l^{10}$ carried out an analysis of the exposureresponse relationship for PMM in five regions of France, their main interest being occupational exposures. They observed a clear trend of increase in the OR according to cumulative exposure, with an OR of 11.3 for subjects continuously exposed to over $10 \mathrm{f} / \mathrm{mL}$-years. Hansen $e t a l^{3}$ carried out a cohort study of $\mathrm{MM}$ in the population living in the town of Wittenoom and observed a steady increase in the incidence rate of MM with all the indicators of intensity and duration of exposure. Howel et $a l^{4}$ found a strong association of MM with residential proximity (closer than $0.5 \mathrm{~km}$ ) to an asbestos exposure source $(\mathrm{OR}=6.6)$. They did not provide quantitative estimation of exposure but a companion paper $^{5}$ measured the association of MM risk with the asbestos lung burden, showing higher concentrations of asbestos fibres in cases than controls. Results of a case-control study on PMM recently published by Lacourt et $a l^{11}$ showed a clear exposure-response relationship between quantitatively assessed occupational exposure and PMM among men. The point estimates of the OR by category of cumulative exposure were strikingly similar to our own results. In the study by Mensi et $a l^{35}$ that evaluated the impact of asbestos cement production on MM incidence in the area of Broni (an Italian town where an AC factory was active in the period 1932-1993), 72 cases of PMM of 138 were attributable to environmental exposure but the study did not evaluate the relation with cumulative exposure. The observed increase in female cases of mesothelioma in the UK, many with no occupational exposure to asbestos, suggested widespread environmental contamination. ${ }^{12}$ Our study clearly shows a relationship between PMM risk and cumulative exposure also after non-occupational exposures. This is a novel result that confirms with quantitative data our previous results from studies in the area ${ }^{17}$ and underlines the need to carefully control all sources of asbestos exposure.

A statistically significant risk of PMM has been repeatedly reported for individuals having family members exposed to asbestos. Howel et $a l^{4}$ showed a strong association of MM with this route of asbestos exposure $(\mathrm{OR}=61.7$ in the stratum without occupational exposure). A two-fold increase in risk was observed by Rake et al ${ }^{12}$ for 'living with an exposed worker before age 30'. Mesothelioma was also reported to occur among wives of asbestos workers in the cohort studies published by Ferrante et $a l^{25}$ and Anderson et al. ${ }^{36}$

Environmental exposures to asbestos combined with domestic exposure were reported to be the cause of epidemics of mesothelioma among people living in villages in Turkey exposed to erionite, ${ }^{37}$ and among people residing in areas of tremolite contamination in Cyprus, ${ }^{38}$ Metsovo $^{39}$ and New Caledonia. ${ }^{40}$

In Casale Monferrato and surrounding towns, the AC factory was reported as the main source of asbestos pollution until 1986; this is also shown by our analysis of the spatial distribution of PMM risk around it. ${ }^{17}$ Other sources, such as $\mathrm{AC}$ roofs or AC tailings may have taken on a progressively more important role (in relative terms) after the factory was closed and, more recently, careful abatement of its asbestos-contaminated site has been completed. In our study, having a garden or courtyard paved with AC tailings, an AC roof or AC buildings near home were associated with a significant increase in the OR. These are currently considered to be potential secondary sources of asbestos pollution. As per our knowledge, no other case-control study reported the evaluation of the risk related to the presence of AC materials in the surroundings of the residence. Our results, albeit based on questionnaire information, indicate the need to evaluate $\mathrm{AC}$ in place as a potential source of risk.
PMM incidence in the Casale Monferrato LHA has risen over the years up to an age-standardised rate of 35.5 (95\% CI 28.7 to 42.4 ) cases per 100000 per year in 2008-2012 among men, and 15.9 (95\% CI 11.6 to 20.1) among women (definite diagnosis). The increasing trend seems to have flattened out during the past few years, since age-standardised incidence rates for 2005-2009 and 2010-2012 periods were similar. ${ }^{14}$ Such high and persistent incidence is a cause for alarm among Casale Monferrato citizens, who sometimes question whether the causes of this epidemic are finally under control. The town has indeed undertaken a massive process of decontamination, including the shutdown of the AC plant and related buildings, the remediation of deposits of tailings and the substitution of AC roofs of public buildings. The programme is continuing and will also include financial and procedural support for renovation of private buildings. Epidemiological surveillance is ongoing to evaluate whether these measures will determine a reduction of MM incidence.

The present work confirms the quantitative relationship between PMM incidence and cumulative exposure to asbestos, even at low levels of exposure. It also underlines the contribution of environmental and familial/domestic asbestos exposures to the occurrence of PMM in the population of Casale Monferrato, with increased risks in relation to $\mathrm{AC}$ in place in the living environment. Continuing epidemiological surveillance and investigation into the specific routes and circumstances of exposures contributing to PMM occurrence in this population is, therefore, important.

Acknowledgements The authors are grateful to the interviewer, Dr Marinella Bertolotti, to Dr Fulvio Lazzarato for geocoding and to Ms Victoria Franzinetti for he careful editing and revision of the text. The authors wish to thank all the patients who kindly participated in the study. The authors also thank Drs Mario Botta, Ezio Piccolini, Daniela Degiovanni, Mansueto Pavesi (S.Spirito Hospital of Casale Monferrato, ASL AL) and Pier Giacomo Betta (Azienda Ospedaliera Nazionale SS Antonio e Biagio e Cesare Arrigo, Alessandria) for their co-operation.

Contributors DF was involved in the statistical analysis and manuscript writing. DM was involved in the exposure assessment and revision of the manuscript. ST was involved in the statistical analysis. BT was involved in the revision of the manuscript. CM did the supervision of each step of this study, from the study design to the revision of the manuscript.

Funding The Casale case-control study was supported by a grant from Regione Piemonte, Ricerca Sanitaria Finalizzata 2004 (to CM) and by the Regione Piemonte, Ricerca Scientifica Applicata 2003 (to DM grant no.258/2003, CM). Analyses for the present study were supported by the Italian National Institute of Health-ISS, 'Progetto Amianto' (to CM).

Competing interests DM and CM acted as expert witnesses for the public prosecutor in criminal trials on asbestos-related cancers.

Patient consent Obtained.

Provenance and peer review Not commissioned; externally peer reviewed.

\section{REFERENCES}

1 IARC. IARC Monographs on the evaluation of carcinogenic risks to humans, vol. 100 C, Arsenic, Metals, Fibres and Dusts. Lyon: IARC Press, 2012.

2 WHO. Elimination of asbestos related diseases. Geneva: World Health Organization, 2006. http://www.who.int/occupational_health/publications/asbestosrelateddisease/ en/ (accessed 17 Jun 2015).

3 Hansen J, de Klerk NH, Musk AW, et al. Environmental exposure to crocidolite and mesothelioma: exposure-response relationships. Am J Respir Crit Care Med 1998; 157:69-75.

4 Howel D, Arblaster L, Swinburne L, et al. Routes of asbestos exposure and the development of mesothelioma in an English region. Occup Environ Med 1997;54:403-9

5 Howel D, Gibbs A, Arblaster L, et al. Mineral fibre analysis and routes of exposure to asbestos in the development of mesothelioma in an English region. Occup Environ Med 1999;56:51-8.

6 Kurumatani N, Kumagai S. Mapping the risk of mesothelioma due to neighbourhood asbestos exposure. Am J Respir Crit Care Med 2008;178:624-9. 
7 Magnani C, Agudo A, Gonzales CA, et al. Multicentric study on malignant pleural mesothelioma and non-occupational exposure to asbestos. Br J Cancer 2000;83: 104-11.

8 Magnani C, Dalmasso P, Biggeri A, et al. Increased risk of malignant mesothelioma of the pleura after residential or domestic exposure to asbestos: a case-control study in Casale Monferrato, Italy. Environ Health Perspect 2001;109:915-19.

9 Gardner MJ, Saracci R. Effects on health of non-occupational exposure to airborne mineral fibres. IARC Sci Publ 1989;90:375-97. Review.

10 Iwatsubo Y, Pairon JC, Boutin C, et al. Pleural mesothelioma: dose-response relation at low levels of asbestos exposure in a French population-based case-control study. Am J Epidemiol 1998;148:133-42.

11 Lacourt A, Gramond C, Rolland P, et al. Occupational and non-occupational attributable risk of asbestos exposure for malignant pleural mesothelioma. Thorax 2014;69:532-9.

12 Rake C, Gilham C, Hatch J, et al. Occupational, domestic and environmental mesothelioma risks in the British population: a case-control study. $\mathrm{Br} J$ Cancer 2009;100:1175-83.

13 Rödelsperger $\mathrm{K}$, Jöckel KH, Pohlabeln $\mathrm{H}$, et al. Asbestos and man-made vitreous fibers as risk factors for diffuse malignant mesothelioma: results from a German hospital-based case-control study. Am J Ind Med 2001;39:262-75.

14 CPO (Piedmont Reference Center for Epidemiology and Cancer Prevention). Malignant Mesothelioma Registry. http://www.cpo.it/workspace/files/ incid-meso-pleurici_2010-52946f875eea2.pdf http://www.cpo.it/workspace/files/ incidenza9012_pl_inglese-54bf7342271a2.pdf (accessed 17 Jun 2015).

15 ReNaM (Italian National Register of Mesothelioma). IV Report. INAIL, 2012.

16 Magnani C, Ferrante D, Barone Adesi F, et al. Cancer risk after cessation of asbestos exposure. A cohort study of Italian asbestos cement workers. Occup Environ Med 2008:65:164-70.

17 Maule MM, Magnani C, Dalmasso P, et al. Modeling mesothelioma risk associated with environmental asbestos exposure. Environ Health Perspect 2007;115:1066-71.

18 International Labour Office. International Standard Classification of occupations. International Labour Office Publications, Geneva, 1968

19 Eurostat. NACE Rev 1. Council Regulation (EEC) No 3037/90 as modified by Commission Regulation (EEC) No 761/93. Unit B 6. Classifications 30/06/1993.

20 Anonimous. Situations de travail exposant à I'amiante. Institut National de Recherche et de Sécurité (INRS), 2007.

21 Anonimous. Evalutil. http://etudes.isped.u-bordeaux2.fr/evalutil003/(S (503ccde223rk31ybz4rxij55))/accueil.aspx (accessed 17 Jun 2015).

22 Peters $\mathrm{S}$, Vermeulen $\mathrm{R}$, Olsson A, et al. Development of an exposure measurement database on five lung carcinogens (ExpoSYN) for quantitative retrospective occupational exposure assessment. Ann Occup Hyg 2012;56:70-9.

23 Bourdes V, Boffetta P, Pisani P. Environmental exposure to asbestos and risk of pleural mesothelioma: review and meta-analysis. Eur J Epidemiol 2000;16:411-17.

24 U.S. EPA. Guidelines for ecological risk assessment. Washington DC: U.S. Environmental Protection Agency, Risk Assessment Forum, EPA/630/R095/002F, 1998.
25 Ferrante D, Bertolotti M, Todesco A, et al. Cancer mortality and incidence of mesothelioma in a cohort of wives of asbestos workers in Casale Monferrato, Italy. Environ Health Perspect 2007;115:1401-5.

26 Wheeler DC, Burstyn I, Vermeulen R, et al. Inside the black box: starting to uncover the underlying decision rules used in a one-by-one expert assessment of occupational exposure in case-control studies. Occup Environ Med 2013;70: 203-10.

27 Friesen MC, Coble JB, Katki HA, et al. Validity and reliability of exposure assessors' ratings of exposure intensity by type of occupational questionnaire and type of rater. Ann Occup Hyg 2011;55:601-11.

28 Peters S, Glass DC, Milne E, et al, Aus-ALL consortium. Rule-based exposure assessment versus case-by-case expert assessment using the same information in a community-based study. Occup Environ Med 2014;71:215-19.

29 Brenner $H$, Loomis D. Varied forms of bias due to nondifferential error in measuring exposure. Epidemiology 1994;5:510-17.

30 Barbieri PG, Mirabelli D, Somigliana A, et al. Asbestos fibre burden in the lungs of patients with mesothelioma who lived near asbestos-cement factories. Ann Occup Hyg 2012;56:660-70.

31 Magnani C, Mollo F, Paoletti L, et al. Asbestos lung burden and asbestosis after occupational and environmental exposure in an asbestos cement manufacturing area: a necropsy study. Occup Environ Med 1998;55:840-6.

32 Hodgson JT, Darnton A. The quantitative risks of mesothelioma and lung cancer in relation to asbestos exposure. Ann Occup Hyg 2000;44:565-601.

33 Barone-Adesi F, Ferrante D, Bertolotti M, et al. Long-term mortality from pleural and peritoneal cancer after exposure to asbestos: possible role of asbestos clearance. Int J Cancer 2008;123:912-16.

34 Pinto C, Novello S, Torri V, et al. Second Italian Consensus Conference on Malignant Pleural Mesothelioma: state of the art and recommendations. Cancer Treat Rev 2013;39:328-39.

35 Mensi C, Riboldi L, De Matteis S, et al. Impact of an asbestos cement factory on mesothelioma incidence: global assessment of effects of occupational, familial, and environmental exposure. Environ Int 2015;74:191-9.

36 Anderson HA, Lilis R, Daum SM, et al. Household contact asbestos neoplastic risk. Ann N Y Acad Sci 1976;271:311-23.

37 Baris I, Simonato L, Artvinli M, et al. Epidemiological and environmental evidence of the health effects of exposure to erionite fibres: a four-year study in the Cappadocian region of Turkey. Int J Cancer 1987;39:10-17.

38 McConnochie K, Simonato L, Mavrides P, et al. Mesothelioma in Cyprus: the role of tremolite. Thorax 1987;42:342-7.

39 Gogali A, Manda-Stachouli C, Ntzani EE, et al. Malignant mesothelioma in Metsovo, Greece, from domestic use of asbestos: 30 years later. Eur Respir J 2012;39: 217-19.

40 Baumann F, Maurizot P, Mangeas M, et al. Pleural mesothelioma in New Caledonia: associations with environmental risk factors. Environ Health Perspect 2011;119:695-700. 